5) Ishikawa, H., T. Murakami, M. Hata and H. Hikita: Chem. Eng. Commun., 34, 123 (1985).

6) Ishikawa, H., H. Nishida and H. Hikita: J. Chem. Eng. Japan, 19, 149 (1986)

7) Ishikawa, H., S. Takase, T. Tanaka and H. Hikita: Biotech. Bioeng., in printing.

8) Mitz, M. A. and R. J. Schlueter: J. Am. Chem. Soc., 81, 4024 (1959).

9) Moo-Young, M. and T. Kobayashi: Can. J. Chem. Eng., 50,
$162(1972)$

10) Pelsy, G. and A. K. Klibanov: Biotech. Bioeng., 25, 919 (1983).

11) Quiocho, F. A. and F. M. Richards: Proc. Nat. Acad. Sci., 52, 833 (1964).

12) Sato, T., T. Mori, T. Tosa and I. Chibata: Arch. Biochem. Biophys, 147, 788 (1971)

13) Weetall, H. H.: Res. Develop., 22, 18 (1971).

\title{
BUBBLE FORMATION AT A SUBMERGED ORIFICE IN NON-NEWTONIAN AND HIGHLY VISCOUS NEWTONIAN LIOUIDS
}

\author{
TOSHIRo MIYAHARA, WEI-HONG WANG AND TERUo TAKAHASHI \\ Department of Applied Chemistry, Okayama University, Okayama 700
}

Key Words: Fluid Mechanics, Bubble Formation, Single Orifice, Non-Newtonian Liquid, Viscous Newtonian Liquid, Biochemical Engineering, Absorption

\begin{abstract}
Bubble formation at a submerged orifice was studied experimentally for non-Newtonian liquids (aqueous CMC solutions) and highly viscous Newtonian liquids (aqueous glycerol solutions). The bubble volumes formed in both non-Newtonian and highly viscous Newtonian liquids are large compared to those formed in relatively low-viscosity Newtonian liquids. The formation regime of the constant-pressure condition, usually found for low-viscosity Newtonian liquids as reported by Tadaki $e t$ al. ${ }^{127}$ was not observed. Using an extended two-stage bubble-formation model, the bubble volumes formed at a submerged orifice in non-Newtonian and highly viscous Newtonian liquids are considered. The predicted bubble volumes compare satisfactorily with the experimental data over a wide range of parameters of power law liquid ( $m<$ around $8 \mathrm{~Pa} \cdot \mathrm{s}^{n}, 0.95>n>0.57$ ) and viscosities of Newtonian liquids $\left(5.05 \mathrm{~Pa} \cdot \mathrm{s}>\mu_{l}>0.439 \mathrm{~Pa} \cdot \mathrm{s}\right)$ including the results of the present work and that of Tsuge $e t$ al. $\left.{ }^{13,15}\right)$
\end{abstract}

\section{Introduction}

Gas-liquid contacting operations such as fermentation, aerobic waste water treatment and polymer production, where most liquids are non-Newtonian and/or highly viscous Newtonian, include processes where gas is dispersed as bubbles through a liquid. However, the phenomena of bubble formation are complex and are not fully described to date. Although bubble formation in relatively low-viscosity Newtonian liquids has been studied extensively, ${ }^{77}$ little attention has been paid to bubble formation in nonNewtonian and/or highly viscous Newtonian liquids.

Costes et al. ${ }^{4-5)}$ reported that in aqueous CMC solutions bubbles are formed under constant-pressure conditions for Reynolds numbers lower than 1000 , while for Reynolds numbers greater than 1000 they are formed under constant-flow rate conditions. They

Received March 36, 1988. Correspondence concerning this article should be addressed to T. Miyahara. also noted that a comparison of theoretical variation of bubble radius with the measurements seems to show that the models of Davidson et al.$^{6)}$ and Kumar et $a l^{7)}$ are in good agreement, but that the former is more suitable than the latter for representing bubble formation. On the other hand, Acharya et al. ${ }^{11}$ compared the data for power-law liquids with those computed using the model of bubble-formation in inviscid liquid and concluded that the rheology of the ambient liquid has no influence on bubble volumes. Rabiger et al. ${ }^{11)}$ proved that single or double bubbles are always formed at the orifice over a wide range of gas throughput in both Newtonian and nonNewtonian liquids. Tsuge et al. ${ }^{13,15-16)}$ recently investigated the effect of various factors on the volume of bubbles formed in highly viscous Newtonian and non-Newtonian liquids in the presence of pressure change in the gas chamber and obtained dimensionless equations for predicting bubble volumes. Thus, in spite of its practical importance, the mechanism of 
bubble formation in non-Newtonian and highly viscous Newtonian liquids remains essentially an unsolved problem.

In previous papers ${ }^{9-10}$ we reported studies of bubble formation with weeping at a submerged orifice, especially the bubble formation pattern and the bubble volume in relatively low-viscosity Newtonian liquids. The present study focuses on bubble formation without weeping in non-Newtonian and highly viscous Newtonian liquids. Experimentally obtained bubble volumes are considered using the dimensionless bubble diameter and the chamber number reported by Tadaki et al., ${ }^{12)}$ and they are compared with the predicted bubble volumes computed from an extended two-stage bubble formation model.

\section{Experimental}

A schematic diagram of the apparatus is given in Fig. 1. A rectangular Plexiglas column of dimensions $16 \times 16 \times 42 \mathrm{~cm}$ contained the liquids employed. Gas (air) from the compressor was fed into the gas chamber via the air filter, the pressure regulator, the buffer tank, the needle valve and finally through the capillary to ensure steady supply. The orifices used were made of brass plate with a thickness of about $1 \mathrm{~mm}$; the details are given in Table 1 . The gas chamber volume varied from 6 to $1045 \mathrm{~cm}^{3}$. The gas was dispersed in the liquids in the form of bubbles. Bubble formation frequency was measured by means of the video system. The gas flow rate was adjusted by the needle valve and measured by the soap-film flow rate meter collecting gas through the funnel near the liquid surface. By assuming that bubbles were all of the same size, the volumes were obtained as the amount of volumetric gas flow rate divided by the frequency. The circulating water jacket, also constructed of Pexiglas, was used to maintain a constant operating temperature. All experiments were carried out with a liquid depth of $25 \mathrm{~cm}$.

Table 2 shows the physical properties of the liquids employed, where aqueous glycerol solutions are
Newtonian liquids and $\mathrm{CMC}$ solutions are nonNewtonian liquids represented by the power law of a two-parameter rheological model of the form

$$
\tau=-m\left(\frac{d u}{d y}\right)^{n}
$$

For $n=1$, it reduces to the Newtonian law of viscosity with $=\mu_{l}$. The deviation of $n$ from unity indicates the degree of deviation from Newtonian behavior.

\section{Results and Discussion}

\subsection{Bubble volume in non-Newtonian and highly vis- cous Newtonian liquids}

In Figs. 2 and 3, the measured bubble volumes in $\mathrm{CMC}$ solutions and glycerol solutions respectively are plotted as a function of the gas flow rates. Bubble

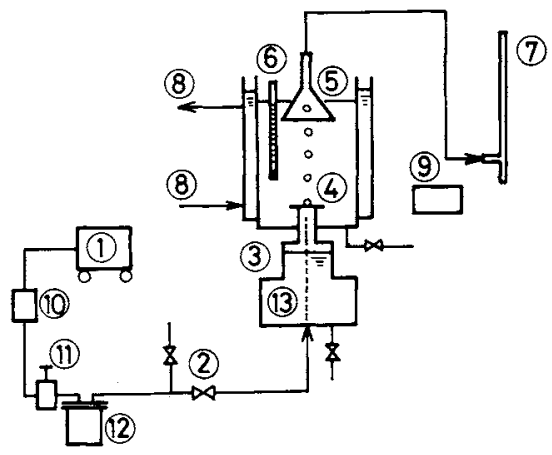

Fig. 1. Schematic diagram of experimental apparatus. 1, compressor; 2, valve; 3 , air chamber; 4, orifice; 5, funnel; 6 , thermometer; 7 , soap-film flow rate meter; 8 , constanttemperature water bath; 9, VTR; 10, air filter; 11 , pressure regulator; 12 , buffer tank; 13 , capillary

Table 1. Geometries of orifices

\begin{tabular}{cccc}
\hline Office No. & $d_{o} \times 10^{3}[\mathrm{~m}]$ & $p_{t} \times 10^{2}[\mathrm{~m}]$ & $p_{t} / d_{o}[-]$ \\
\hline 1 & 3.19 & 0.109 & 0.341 \\
2 & 2.05 & 0.102 & 0.497 \\
3 & 1.00 & 0.102 & 1.02 \\
4 & 0.80 & 0.101 & 1.26 \\
5 & 0.50 & 0.103 & 2.06 \\
\hline
\end{tabular}

Table 2. Physical properties of liquids employed

\begin{tabular}{cccccc}
\hline Liquid & $\mu_{i}[\mathrm{~Pa} \cdot \mathrm{s}]$ & $m\left[\mathrm{~Pa} \cdot \mathrm{s}^{n}\right]$ & $n[-]$ & $\sigma[\mathrm{N} / \mathrm{m}]$ & $\rho_{l}\left[\mathrm{~kg} / \mathrm{m}^{3}\right]$ \\
\hline Aqueous CMC solution 1 & - & 0.275 & 0.950 & $68.0 \times 10^{-3}$ & 1003 \\
Aqueous CMC solution 2 & - & 1.688 & 0.768 & 73.0 & 1005 \\
Aqueous CMC solution 3 & - & 1.740 & 0.770 & 73.0 & 1005 \\
Aqueous CMC solution 4 & - & 5.820 & 0.740 & 74.0 & 1008 \\
Aqueous CMC solution 5 & - & 13.950 & 0.639 & 67.0 & 1012 \\
Aqueous CMC solution 6 & - & 29.800 & 0.460 & 67.0 & 1012 \\
Aqueous CMC solution 7 & - & 31.300 & 0.403 & 67.0 & 1012 \\
\hline Glycerol 1 & 1.100 & - & - & 68.0 & 1258.5 \\
Glycerol 2 & 2.300 & - & - & 67.5 & at $25^{\circ} \mathrm{C}$ \\
\hline
\end{tabular}




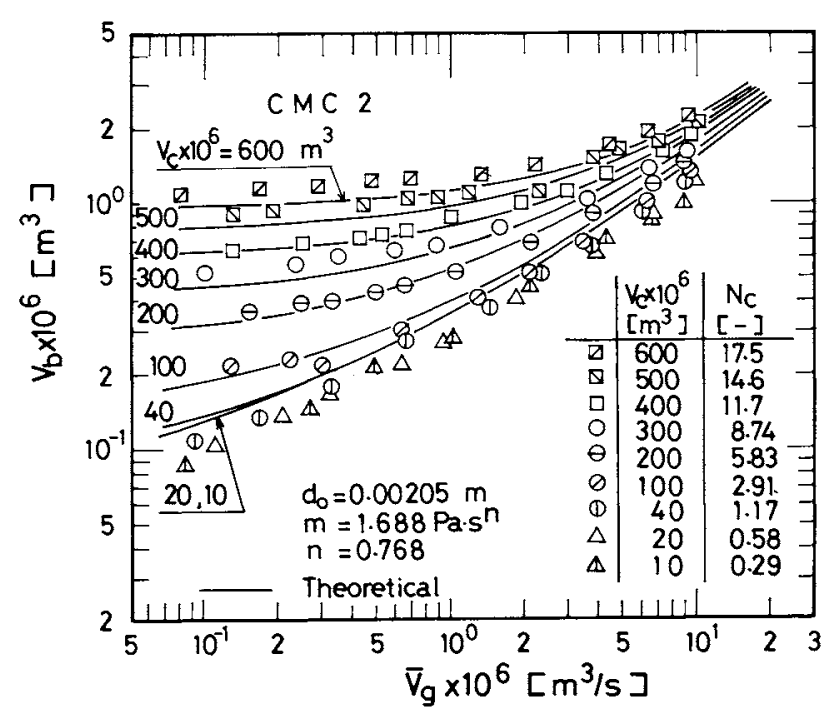

Fig. 2. Bubble volume in aqueous $\mathrm{CMC}$ solution

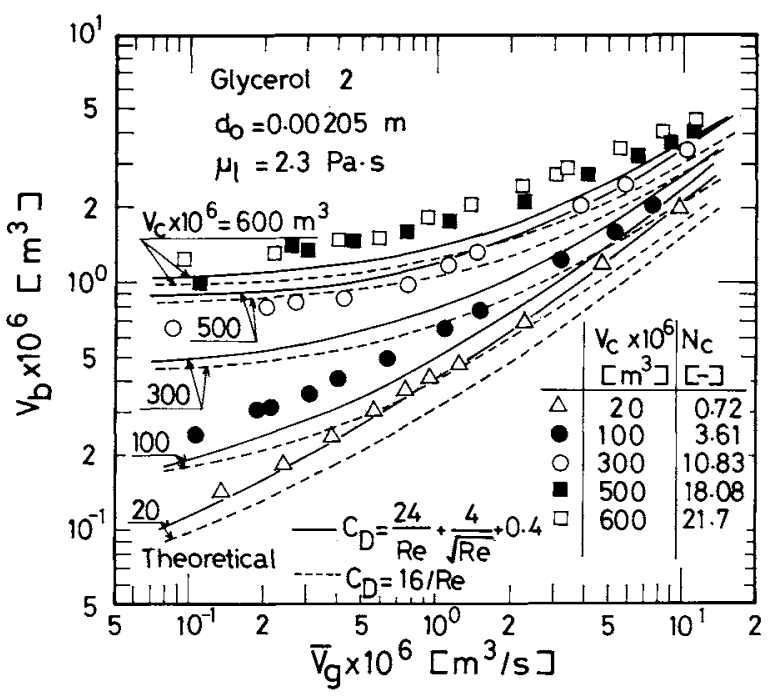

Fig. 3. Bubble volume in glycerol volumes increase with increasing chamber volume; the effect of chamber volume is especially remarkable at low gas flow rates. Similar trends were found for bubble formation without weeping ${ }^{12)}$ as well as with weeping $^{9-10}$ ) in relatively low-viscosity Newtonian liquids. Figures $\mathbf{4}$ and $\mathbf{5}$ show the effect of two parameters of non-Newtonian liquids and the effect of viscosity of Newtonian liquids. It is apparent that the bubble volumes increase as both the rheological parameter $m$ and the viscosity of Newtonian liquid increase.

Tadaki et al. ${ }^{12)}$ proposed the following correlations for bubble formation without weeping at low gas flow rates in relatively low-viscosity Newtonian liquids.

$$
\begin{aligned}
& d_{b}\left\{g \rho_{l} /\left(\sigma d_{o}\right)\right\}^{1 / 3}=1.82 \quad N_{c}<1 \\
& d_{b}\left\{g \rho_{l} /\left(\sigma d_{o}\right)\right\}^{1 / 3}=1.82 N_{c}^{1 / 3} \quad 1<N_{c}<9 \\
& d_{b}\left\{g \rho_{l} /\left(\sigma d_{o}\right)\right\}^{1 / 3}=3.8 \quad N_{c}>9
\end{aligned}
$$

These correlations are shown in Fig. $\mathbf{6}$ as solid lines. Tadaki et al. ${ }^{12)}$ also suggested that the regimes of $N_{c}<1, \quad 1<N_{c}<9$ and $N_{c}>9$ correspond to the constant-flow rate condition, the condition of pressure fluctuation in the gas chamber, and the constant-pressure condition, respectively. Note that the constant-pressure condition is not found for the present results, although Costes et al. ${ }^{4-5)}$ found that formation of bubbles in non-Newtonian liquids can take place under the constant-pressure condition at low flow rates and under the constant-flow rate condition at high gas flow rates. As can be seen from the figure, the bubble volumes in highly viscous Newtonian and in non-Newtonian liquids are large compared to those in low-viscosity Newtonian liquids. These differences may be due to the effect of viscosity and rheological parameters. We next try to correlate the measurements using an extended two-

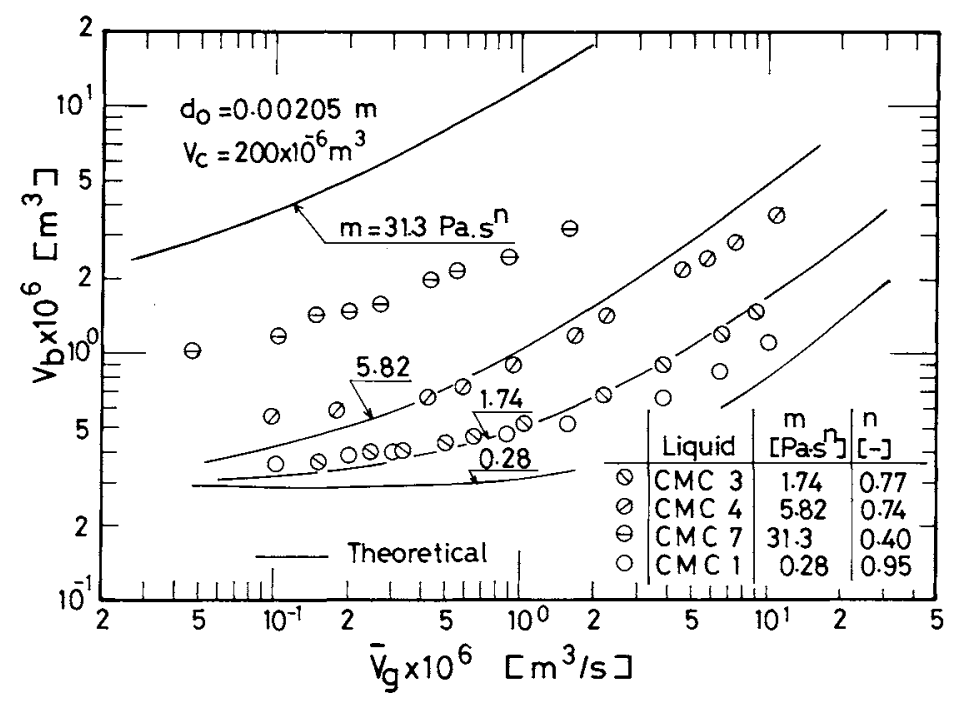

Fig. 4. Bubble volume in aqueous CMC solution 
stage bubble-formation model.

\subsection{Prediction of bubble volume from an extended two-stage bubble-formation model}

The authors ${ }^{9-10)}$ have already proposed a theoretical model for bubble formation with weeping and taking into account the effect of viscosity, using a two-stage model. Here, we will try to extend the same two-stage process for bubble formation in nonNewtonian liquids. From the observation of bubble formation with a video camera, it was found that initially an almost spherical bubble is formed at an orifice, proceeds to grow a neck and detaches. This reflects the validity of two-stage bubble formation in both highly viscous Newtonian and non-Newtonian liquids.

For the case of a spherical bubble growing in an incompressible liquid of infinite extent and negligible gas moment, the equation of bubble growth is assumed to be generally expressed for a rising, expanding bubble as follows ${ }^{8,10)}$.

$$
\begin{aligned}
P_{b}= & \rho_{l}\left\{\left(\frac{3}{2}\right)\left(\frac{d a}{d t}\right)^{2}+a \frac{d^{2} a}{d t^{2}}-g s\right\} \\
& -\frac{\rho_{l}}{4}\left(\frac{d s}{d t}\right)^{2}+\frac{2 \sigma}{a}+P_{\infty}+F(k)
\end{aligned}
$$

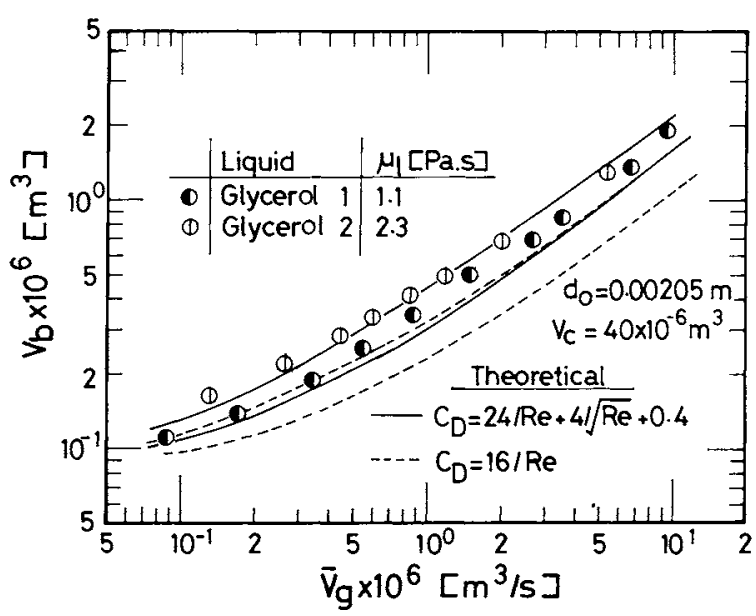

where $F(k)$ is a function of the rheological parameters. However, it is quite difficult to derive theoretically the form of $F(k)$ for real non-Newtonian liquids.

Burman et $a l .^{3)}$ derived theoretically the $F(k)$ for an expanding bubble by solute diffusion in nonNewtonian (power law) liquids using the equation of continuity and momentum as

$$
F(k)=\frac{12^{(n+1) / 2} m}{3 n}\left(\frac{1}{a} \frac{d a}{d t}\right)^{n}
$$

For $n=1$, Eq. (6) is the viscosity term in a modified Rayleigh equation ${ }^{15)}$ commonly used for the growth of bubbles in viscous liquids. In a strict sense, though it is not correct to apply Eq. (6) for the present condition - that is, the rising, expanding bubble-we take Eq. (6) as an approximation of $F(k)$. Hence, we obtain for the first stage

$$
\begin{aligned}
P_{b}= & \rho_{l}\left\{\left(\frac{3}{2}\right)\left(\frac{d a}{d t}\right)^{2}+a \frac{d^{2} a}{d t^{2}}-g s\right\}-\frac{\rho_{l}}{4} v^{2} \\
& +\frac{2 \sigma}{a}+P_{\infty}+\frac{12^{(n+1) / 2} m}{3 n}\left(\frac{1}{a} \frac{d a}{d t}\right)^{n}
\end{aligned}
$$

and

$$
\begin{aligned}
P_{b}= & \rho_{l}\left\{\left(\frac{3}{2}\right)\left(\frac{d a}{d t}\right)^{2}+a \frac{d^{2} a}{d t^{2}}-g s\right\}-\frac{\rho_{l}}{4} v^{\prime 2} \\
& +\frac{2 \sigma}{a}+P_{\infty}+\frac{12^{(n+1) / 2} m}{3 n}\left(\frac{1}{a} \frac{d a}{d t}\right)^{n}
\end{aligned}
$$

for the second stage.

Table 3 summarizes the fundamental equations for the two-stage bubble-formation model obtained by the authors ${ }^{10)}$ previously. The termination of the first stage can be expressed by Eq. (T-1) in the regime of the presence of pressure fluctuation in the gas chamber, and the equation of motion for the second stage is Eq. (T-2).

Equations (7), (T-3), (T-5) and (T-6), the equations for the first stage, can be solved for the initial conditions $P_{c}=P_{o}+\rho_{l} g h+4 \sigma / d_{o}, d a / d t=0$ and $a=d_{o}$ using Eq. (T-1) in Table 3 as the termination con-

Fig. 5. Bubble volume in glycerol

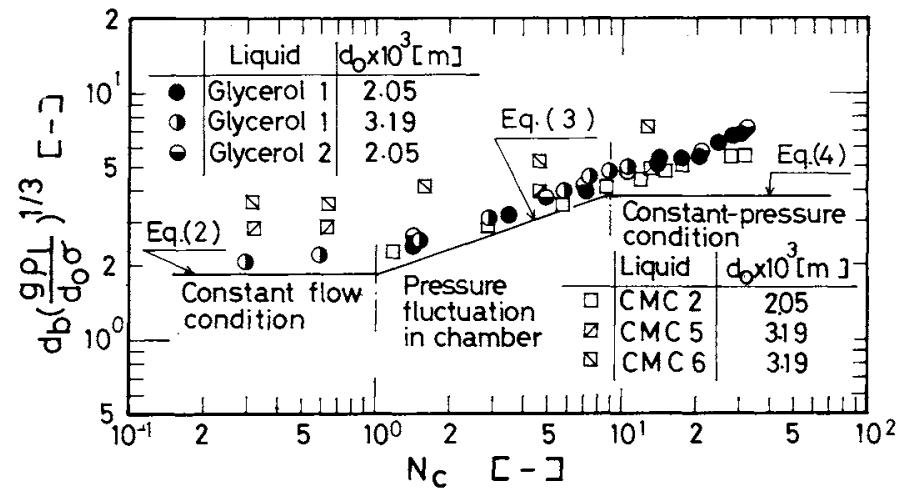

Fig. 6. Comparison of bubble diameters in the range of constant bubble volume with the correlations of Tadaki et $a l^{12}$ ) 
Table 3. Fundamental equations for two-stage bubble formation ${ }^{101}$

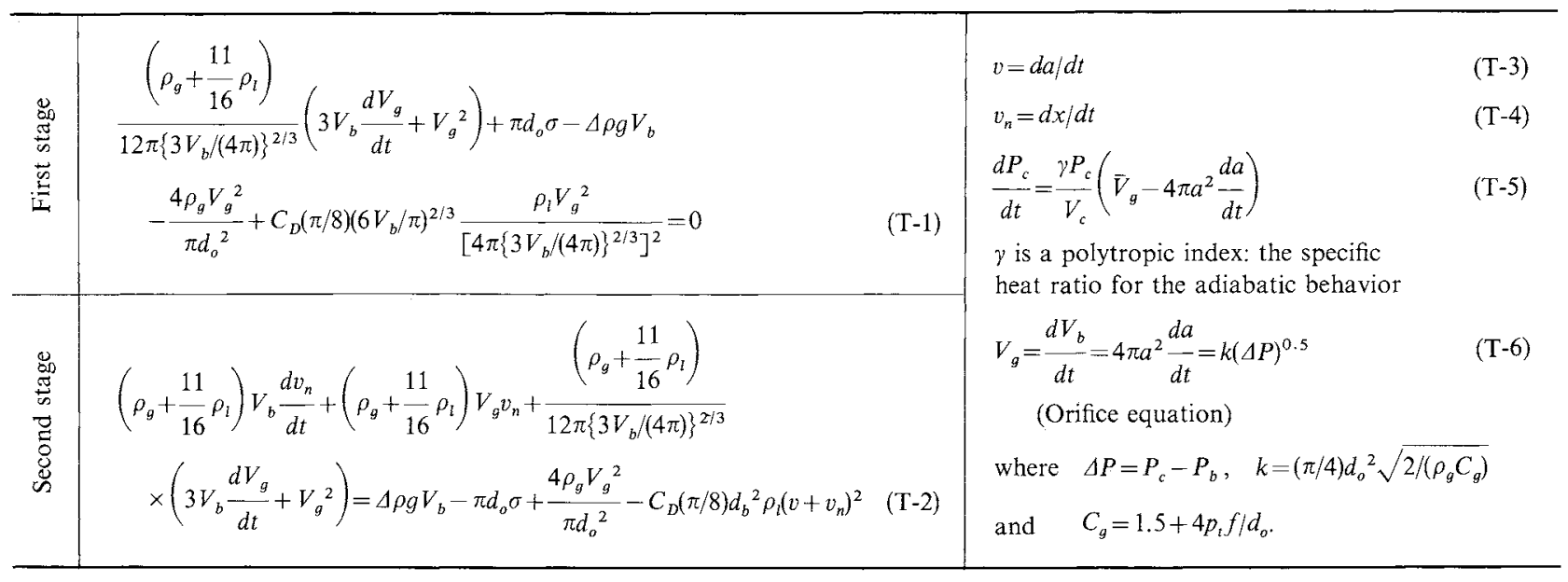

dition. For the second stage, Eqs. (8), (T-2), (T-3), (T4), (T-5) and (T-6) can be solved simultaneously under the initial conditions, $P_{c}=\left(P_{c}\right)_{f}, d a / d t=(d a / d t)_{f}$, $a=a_{f}$ and $x=0$, and the final condition $x=a_{f}$ or $d a /$ $d t=0$ as described previously. ${ }^{10)}$ The above simultaneous differential equations are solved numerically by the Runge-Kutta-Gill method to obtain the bubble volume. For $n=1$, these equations can be applied to a Newtonian liquid with $m=\mu_{l}$.

The curves in Figs. 2, 3, 4 and 5 represent the calculated results using the following correlations as the drag coefficient for non-Newtonian liquids:

$$
C_{D}=16 F(n) / R e^{\prime}
$$

where $F(n)=3^{(n-1) / 2} 2^{(n-1) / 2}\{1-7.66(n-1) / 2\}$, and:

$$
C_{D}=24 / R e+4 / R e^{0.5}+0.4
$$

for highly viscous Newtonian liquids. The validity of Eq. (9) for power law liquids was confirmed by Bhauraju et al. ${ }^{2)}$ and Eq. (10) is a modified Stokes' equation. ${ }^{14)}$ For comparison, the dashed lines in Figs. 3 and 5 show the calculated results by using the Hadamard-Rybzynski equation ${ }^{14)}$ applicable to slow viscous flow past a sphere and reflecting its internal circulation.

$$
C_{D}=16 / R e
$$

The calculated curves for highly viscous Newtonian liquids fit well with the measurements. However, as can be seen from Fig. 4, the discrepancy between theory and experiment for non-Newtonian liquids sharply increases with an increase in the rheological parameter $m$. Further, we compared the present prediction with other investigators' findings ${ }^{13,15)}$ where glycerol solutions $\left(0.439<\mu_{l}<5.05 \mathrm{~Pa} \cdot \mathrm{s}\right)$ and $\mathrm{CMC}$ solutions $\left(1.05<m<25.0 \mathrm{~Pa} \cdot \mathrm{s}^{n}, 0.38<n<0.852\right)$ were employed. Agreement between theory and experiment was generally good for glycerine solutions and nonNewtonian liquids having smaller $m$. Perhaps the
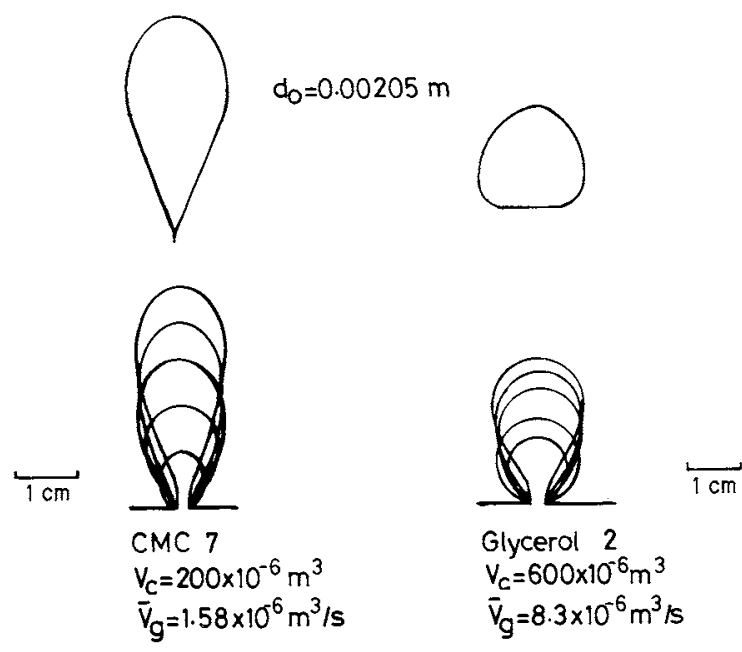

Fig. 7. Bubble formation pattern

most likely reason for the deviation in bubble volume behavior from theoretical predictions for nonNewtonian liquids is that bubbles become nonspherical in shape at large rheological parameters, and that inertial force is dominant rather than forces based on bubble shape such as drag force. Figure 7 shows bubble formation patterns derived from the video camera views of both Newtonian and nonNewtonian liquids. As seen from the photographs, the bubble during formation in a glycerine solution is almost spherical, whereas in a CMC solution the vigorous motion of the liquid presumably causes vertical motion of the bubble; longer bubbles are formed. Further, the two-stage bubble-formation process described above is confirmed here, too. Figure 8 illustrates the relative standard deviation between the calculated values and the measurements for nonNewtonian liquids defined by the following equation.

$$
s^{\prime}=\sqrt{\frac{\sum\left(\frac{V_{b \exp }}{V_{b c a l}}-1\right)^{2}}{N}}
$$




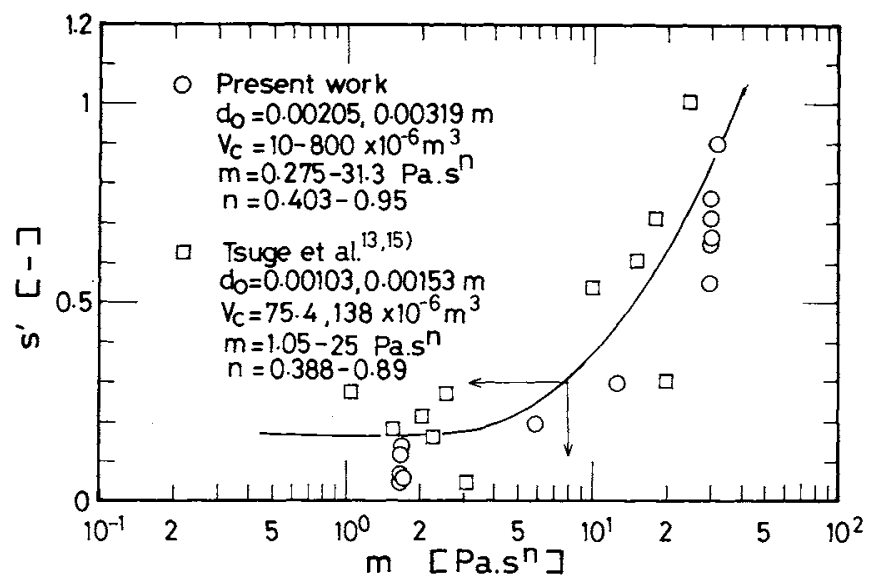

Fig. 8. Relative standard deviation

The figure shows good agreement with the measurements when the rheological parameter $m$ is less than about $8 \mathrm{~Pa} \cdot \mathrm{s}^{n}$.

\section{Concluding Remarks}

The effects of rheological parameters of power law liquids and viscosities of Newtonian liquids on the bubble volume formed at a submerged orifice were investigated experimentally. An extended two-stage bubble formation model was developed to predict the bubble volume. The model accounts for the effect of rheological parameters of power law liquids and the effect of viscosity of Newtonian liquids. The following results were remarked:

1) The volume of a bubble in non-Newtonian and highly viscous Newtonian liquids is large compared to that in relatively low-viscosity Newtonian liquids.

2) The formation regime of the constant-pressure condition was not observed.

3) An extended bubble-formation model taking into account the above effects is found to compare satisfactorily with the measurements.

\section{Nomenclature}

$\begin{array}{ll}a & =\text { bubble radius } \\ C_{D} & =\text { drag coefficient } \\ C_{g} & =\text { orifice coefficient } \\ d_{b} & =\text { bubble diameter } \\ d_{o} & =\text { orifice diameter } \\ F(k) & =\text { defined by Eq. }(5) \\ f & =\text { Fanning's friction factor } \\ g & =\text { gravitational acceleration } \\ h & =\text { liquid depth } \\ k & =\text { constant } \\ m & =\text { coefficient in power law } \\ N & =\text { number } \\ N_{c} & =\text { chamber number } \\ & =4 V_{c} \Delta \rho g /\left\{\pi d_{o}^{2}\left(P_{o}+\rho_{l} g h\right)\right\} \\ n & =\text { power law liquid exponent } \\ P_{b} & =\text { pressure in a bubble } \\ P_{c} & =\text { pressure in gas chamber } \\ P_{o} & =\text { barometric pressure } \\ p_{l} & \end{array}$

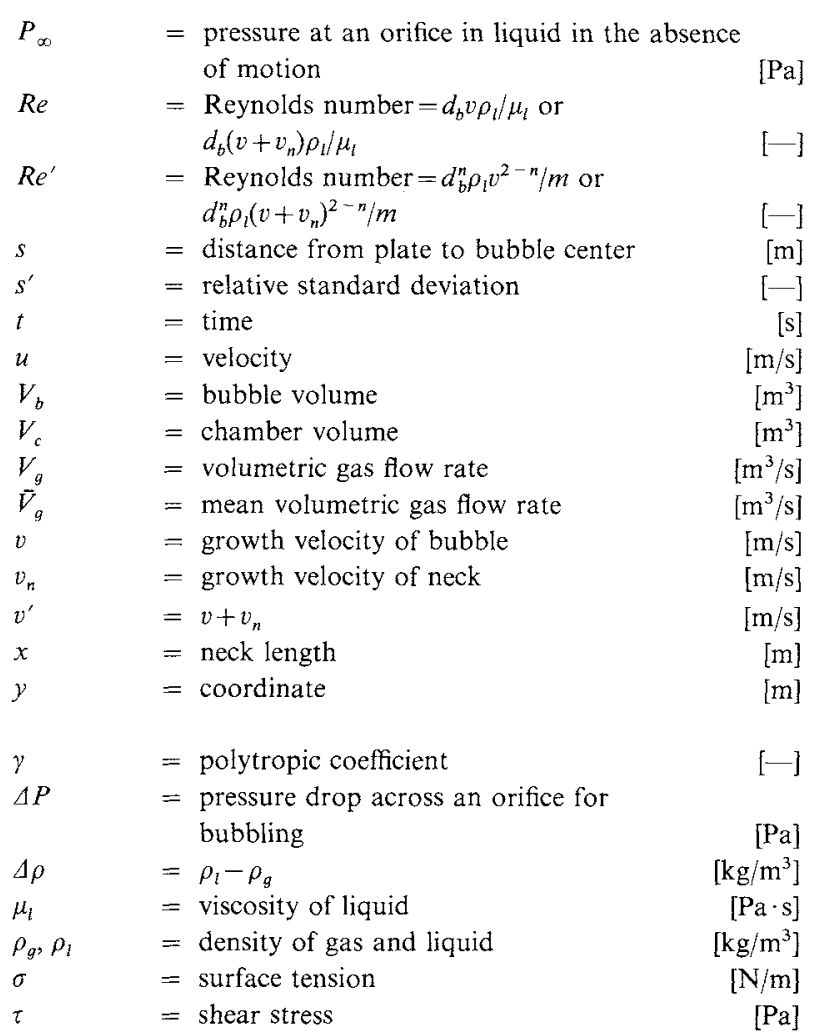

〈Subscript〉

$f \quad=$ value at end of first stage

\section{Literature Cited}

1) Acharya, A., R. A. Mashelkar and J. J. Uibrecht: Ind. Eng. Chem., Fundam., 17, 230 (1978).

2) Bhauraju, S. M., R. A. Mashelkar and H. W. Blanch: AIChE $J ., 24,1063$ (1978).

3) Burman, J. E. and G. J. Jameson: Int. J. Multiphase Flow, 21, 127 (1978).

4) Costes, J. and C. Alran: Int. J. Multiphase Flow, 4, 535 (1978).

5) Costes, J. and C. Alran: The Chemical Engineer, March, 191 (1978).

6) Davidson, J. F. and B. O. G. Shuler: Trans. Instn. Chem. Engrs., 58, 144 (1960).

7) Kumar, R. and N. R. Kuloor: Adv. Chem. Eng., 8, 255 (1970).

8) McCann, D. J. and R. G. H. Prince: Chem. Eng. Sci., 24, 801 (1969). 
9) Miyahara, T., M. Iwata and T. Takahashi: J. Chem. Eng. Japan, 17, 592 (1984).

10) Miyahara, T. and T. Takahashi: J. Chem. Eng. Japan, 17, 597 (1984).

11) Rabiger, N. and A. Vogelpohl: Encyclopedia of Fluid Mechanics, Vol. 3, Chapter 4, N. P. Chremisinoff, Ed., Gulf Publishing Co. (1986).

12) Tadaki, T. and S. Maeda: Kagaku Kōgaku, 27, 147 (1963).

13) Tozawa, K., K. Terasawa, H. Tsuge and S. Hibino: Preprint for the 20th Autumn Meeting of the Soc. of Chem. Engrs., Japan, Himeji, SN-314 (1987).
14) Tsuge, H.: Encyclopedia of Fluid Mechanıcs, Vol. 3, Chapter 9, N. P. Chremisinoff, Ed., Gulf Publishing Co. (1986).

15) Tsuge, H., K. Terasaka and S. Hibino: Proceedings of World Congress III of Chemical Engineering, Tokyo, 7b-351, 308 (1986).

16) Tsuge, H., K. Terasaka, K. Tozawa and S. Hibino: Kagaku Kogaku Ronbunshu, 13, 857 (1987).

(A part of this paper was presented at the 20th Autumn Meeting of The Soc. of Chem. Engrs., Japan at Himeji, October 1987.)

\title{
DEVELOPMENT OF A LANGUAGE THAT ALLOWS BOTH PROCEDURAL AND INFERENTIAL PROGRAMMING AND ITS APPLICATION TO RULE- BASED CONTROL
}

\author{
Chiaki KURODA, Mamoru TOMITA, Gil C. CASTILLO \\ AND MASARU ISHIDA \\ Research Laboratory of Resources Utilization, Tokyo Institute of Technology, \\ Yokohama 227
}

Key Words: AI, Process Control, Rule Base, Prolog, Hybrid Language

\begin{abstract}
A computer language that allows both procedural and inferential programming was developed. In this language, an inference engine of first-order predicate calculus similar to Prolog was installed in a FORTH-like procedural language "The IntelligenT (TIT)." Hence one can execute the inferential treatment inside procedural routines. In addition, one can add procedural operation to the inference. This language was applied to rule-based control for a system with long dead time such as control of temperature of an air stream caused by natural convection. The rules are written as if-then expressions. Since these rules are not given by a procedural program but rather as a rule-base, their description and modification are quite easy. Satisfactory control was achieved by this rule-based controller.
\end{abstract}

\section{Introduction}

To select an AI tool or language is an essential factor when we want to apply knowledge engineering to the fields of chemical engineering. AI tools or languages have inference engines with knowledge bases and are generally designed to treat a set of symbols. On the other hand, chemical engineering problems require many subroutines with complex calculations and many interfaces connected to sensors and actuators.

Ideally speaking, therefore, we need some language in which low-level treatment such as communication through $\mathrm{A} / \mathrm{D}$ and $\mathrm{D} / \mathrm{A}$ interfaces is expressed by machine languages, middle-level treatment such as mathematical calculations is expressed by functional equations, and high-level treatment such as inference based on predicate calculus is expressed by AI languages. Such a language will open new possibilities in the field of computer application.

In this study we have developed a hybrid language in which both procedural parts and inferential parts are included in a program, and these two parts can be compiled simultaneously. In the procedural parts, machine codes, statements and equations can be used, while in the inferential parts, unification can be applied in a way similar to that of Prolog. This language was implemented in a personal computer PC-9801 (NEC Ltd.) and was applied to rule-based control for a system which has a long dead time. 